\title{
POLÍTICA INDÍGENA Y MOVIMIENTOS ETNOPOLIITICOS EN LA ARGENTINA CONTEMPORÁNEA. UNA APROXIMACIÓN DESDE LA ANTROPOLOGÍA SOCIAL
}

Indigenous Politics and Ethnopolitical Movements in contemporary Argentine. An approach from Social Anthropology

JUAN CARLOS RADOVICH *

\section{Resumen}

En el presente trabajo nos proponemos describir y analizar desde la perspectiva de la Antropología Social, algunas políticas públicas desarrolladas hacia los pueblos indígenas de la Argentina, como así también analizar el papel desempeñado por algunos movimientos etnopolíticos en la lucha por la obtención de derechos específicos concernientes a dichos pueblos en la historia contemporánea del país.

Palabras Clave: Política, Indígenas, Movimientos etnopolíticos, Argentina

\section{Abstract}

The main goal of this article is to describe and analyze from the scope of Social Anthropology, the public policies developed towards indigenous peoples in Argentina. In addition, we shall analyze the role played by ethnic movements in their struggle to obtain the recognition of several rights during contemporary history of the country.

Key words: Politics, Indigenous people, Ethnic movements, Argentina

\footnotetext{
* Doctor en Antropología. Profesor Titular en la Facultad de Filosofía y Letras de la Universidad de Buenos Aires (FFyLUBA). Investigador Principal del CONICET en el Instituto Nacional de Antropología y Pensamiento Latinoamericano (INAPL), Buenos Aires, Argentina. Correo electrónico: radovich@retina.ar
} 


\section{Introducción}

La República Argentina, país de inmigración edificado sobre el genocidio de los pueblos indígenas (ocurrido hacia finales del siglo XIX), construyó a través de sus elites dominantes y mediante un modelo cultural hegemónico, una autoimagen idealizada de país europeo en clave liberal/oligárquica, cuyo máximo paradigma enunciativo fue el denominado "Crisol de razas". Ello posibilitó la construcción de una imaginaria identidad diferenciada y contrastante con respecto al resto de América Latina. Luego de la última dictadura militar (1976-1983) y con la recuperación de un régimen republicano $y$, constitucional (10/12/1983), se produjeron una serie de avances en el plano legislativo y en el de las políticas públicas relacionadas con los pueblos originarios y las minorías, las cuales no lograron en cierta medida consolidarse y concretarse en acciones eficaces para evitar las practicas xenófobas y discriminatorias hacia ciertos "otros" internos, representados por los pueblos originarios y los inmigrantes de algunos países limítrofes (Bolivia, Chile, Paraguay, Perú, etc.). También debemos agregar que, durante este período aciago de la historia argentina, la represión extendida hacia todos los sectores populares también afectó como era de esperar a las organizaciones indígenas, las cuales sufrieron represión y violencia en todas sus variantes.

Por otra parte, en la Argentina se han realizado diversos estudios desde la perspectiva antropológica, acerca de la política indígena y el surgimiento y desarrollo de organizaciones indígenas en función de la puesta en práctica de reclamos y reivindicaciones de derechos conculcados (Balazote \& Radovich, (1999);
Bartolomé \& Robinson 1984; Briones \& Carrasco (2000); Gorosito Kramer (1992); Lenton (2010 a y b); Hidalgo \& Tamagno (1992); Kropff (2005); Radovich, (1992; 1999; a y b; 2007; 2011); Radovich \& Balazote (1999 a, b y c); Reynoso (1988); Serbín (1981); Slavsky (1987); Tamagno (2009); Trinchero \& Leguizamón (1995); Valverde (2003); Vázquez (2000). Todos estos trabajos citados, solo constituyen una muestra fragmentaria e incompleta de la producción efectuada durante las últimas décadas. No es nuestro objetivo analizarlas críticamente ni en forma detallada, aunque es una tarea que nos debemos a futuro, dado que los diversos enfoques y líneas de investigación difieren en cuanto a los planteos delineados para abordar un aspecto tan crucial y complejo como es la cuestión indígena en la Argentina.

\section{El Estado nacional y sus políticas hacia los pueblos originarios}

Luego del sometimiento militar de los pueblos originarios llevado a cabo mediante un proyecto de exterminio y sumisión, como fueron la eufemísticamente denominada "Campaña al Desierto" hacia el sur del territorio nacional, en 1879, liderada por el general Julio A. Roca y, la posterior Conquista de la región Chaqueña en el noroeste del país, con la campaña del general Benjamín Victorica en 1884.

La primera de las campañas mencionadas tuvo una gran importancia económica, dado que "Las tierras conquistadas sumaban 60 millones de has. Prácticamente la superficie de explotación económica se había duplicado (...)" (Tur, 1972:73). Desde 1876 hasta la finalización del siglo XIX, los distintos gobiernos nacionales entregaron más de las dos terceras partes de las tierras conquistadas 
a un número muy reducido de individuos vinculados con los factores de poder político y económico. Resulta imprescindible señalar que las operaciones militares fueron financiadas principalmente por la clase terrateniente, interesada en ampliar sus posibilidades económicas, a través de la participación en un "empréstito patriótico" que fue pagado con la entrega de tierras en propiedad una vez finalizada la campana (Viñas \& Gastiazoro, 1968). La incorporación de los territorios indígenas a la esfera de control estatal, trajo aparejada la inmediata privatización de importantes extensiones de territorio. Todo ello conduce a caracterizar a este momento, tal como señala Tur, que "En esta nueva etapa se asienta y consolida el predominio del latifundio ganadero y los inmigrantes agricultores queden subordinados a los requerimientos del desarrollo pecuario (Tur, 1972:48). Al respecto señala Páez, “(...) 24 personas recibieron parcelas que oscilaban entre las 200 y las 650 mil hectáreas" (Páez, 1970:111). De esta manera, las clases dominantes de la Argentina de finales del siglo XIX, enarbolando las banderas del progreso y la modernidad, lograron imponer un modelo en el cual, "El progreso (consistió en) el exterminio del indio o su doma ciudadanizante (...) y la modernidad (...) el extasiante holocausto de la racionalidad indígena" (García Linera, 2008: 193).

Un concepto clave, que ha servido como basamento de esta construcción legitimadora lo constituye la noción de "pionerismo", atribuido a los contingentes de inmigración europea relativamente reciente que iniciaron la reconversión de las regiones chaqueña y patagónica, luego de la derrota militar de los pueblos originarios. Dicho concepto de pionerismo como forma ideológica, está asociado a una visión de primordialismo histórico al referir el comienzo de las historias regionales y locales, al momento de repoblamiento y reemplazo de la población aborigen y, como punto de partida de un proyecto homogeneizante que unificaría a toda la sociedad bajo la bandera del "progreso".

De este modo, la incorporación de los pueblos originarios al capitalismo respondió a un doble mecanismo de expansión y de profundización del sistema a través de la violencia sistemática. Así fue como las regiones conquistadas fueron afectadas por movimientos poblacionales y nuevas formas de ocupación territorial, como consecuencia de las actividades militares mencionadas y la aplicación del modelo económico dominante.

Por otra parte, ya desde las primeras décadas del pasado siglo $X X$, mediante la ejecución de diversas políticas hacia el sector indígena desde el Estado nacional en Argentina, usualmente se ha confundido "diferencia" con "desigualdad", al suponer desde las ideologías basadas en el "progreso" y el "desarrollo", que suprimiendo las diferencias, indefectiblemente se superarían las desigualdades sociales. Dicha postura, marcadamente asimilacionista que propiciaba políticas de "desarrollo", partía del planteo basado en un modelo bipolar que contemplaba la oposición "moderno/atrasado", en la cual los aborígenes estaban incluidos en el segundo término del binomio, mientras que la situación de pobreza y estancamiento en que se encontraban estaban relacionadas con sus "características culturales", convirtiéndose de este modo en los únicos responsables de su situación. El polo moderno, a su vez, era definido en términos de gran dinamismo, mientras que el atrasado permanecía estático en términos de "evolución" o "desarrollo", hallándose las carencias de este último, presentes en el primero. Según este enfoque, la situación de atraso solo podría superarse mediante la "imposición" 
de las características del sector moderno "(...) mediante medidas drásticas de saneamiento, de alfabetización, de promoción de fuentes de trabajo (...)" (Reynoso, 1986:141). De este modo, la diversidad constituiría una "anomalía" a ser superada mediante el progreso que conlleva la modernización, entendida como urbanización, escolarización, industrialización y capacitación laboral.

Sobre estos supuestos se basaron las políticas indigenistas durante muchas décadas en el continente americano, orientando sus acciones a través de políticas asimilacionistas e integracionistas, cuyo fin último era el de lograr una "transfiguración étnica" (Ribeiro, 1997) de los pueblos, para convertirlos en "ciudadanos genéricos" bajo una supuesta igualdad de derechos. Evidentemente, esto último no se logró y la discriminación y, exclusión de los indígenas, se constituyó en una constante en las sociedades latinoamericanas.

Otra postura teórica, sobre la cual se basan ciertas interpretaciones de la cuestión indígena, es aquella denominada "preservacionista" o "conservacionista", "(...) que propugna el reconocimiento de las etnias indígenas como entidades culturales independientes, postulando la necesidad de preservar hasta el último fragmento de los comportamientos e instituciones arcaicas" (Reynoso, 1986:141). Este enfoque no obstante ciertas pretensiones de revalorización y protección, continúa considerando a los pueblos originarios como "aislados, autónomos", contribuyendo a su naturalización y cosificación ${ }^{1}$. Esta postura se relaciona con el denominado "indianismo ecologista", cuya rasgo distintivo consiste en considerar el par indígena/naturaleza en perfecta armonía entre sí “(...) inalterada en la comunidad de un ciclo vital ininterrumpido y víctimas inocentes de la corrupción de occidente: la polución y el deterioro, con sus secuelas de pobreza, miseria y 'aculturación' (...)” (Gorosito Kramer, 1989:7). Frecuentemente, este enfoque es asumido de un modo acrítico por algunas organizaciones indígenas, como forma de argumentación en el proceso de lucha política por la obtención de derechos en los distintos estados latinoamericanos, aunque sin percibir con claridad la problemática estructural de su situación de desigualdad social. Hacia finales de la década del sesenta y comienzos de la del setenta, se constituye un momento clave, en el cual las embrionarias organizaciones indígenas retoman con mayor fuerza las luchas de sus antecesores, en una coyuntura en donde la politización de la sociedad estaba a la orden del día. Fue un período particularmente importante en el desarrollo organizativo de los pueblos originarios de América Latina, en general y, de la Argentina en particular.

En este país se había realizado el primer Censo Indígena Nacional, planificado durante el gobierno del presidente Arturo H. Illia (1963-1966) y continuado durante la antepenúltima dictadura militar (1966-1973), cuyos resultados quedaron inconclusos debido a problemas metodológicos a la hora de cómo definir a las comunidades indígenas $\mathrm{y}$, principalmente, debido a que desaparecieron las cédulas censales en el Ministerio de Bienestar Social de la Nación durante la gestión de José López Rega (1973-1974).

En 1968 se fundó el Centro Indígena en Buenos Aires; en 1970 se creó la Confederación Indígena Neuquina (Lenton, 2010 b: 91). En 1971 se crea la Comisión Coordinadora de Organizaciones Indígenas, integrada en su mayoría por dirigentes de distintos pueblos 
que habitaban en la ciudad de Buenos Aires. En el mismo año se produjo la I Declaración de Barbados, durante la cual un grupo de antropólogos emitió un documento denominado "Por la liberación del Indígena", en el que se realizaba un análisis crítico sobre el rol de la Antropología², los Estados y las distintas iglesias en la situación de sometimiento sufrida por los pueblos originarios del continente ${ }^{3}$. En 1972 se reúne el Primer Parlamento Indígena Nacional en Neuquén, en el cual se trazaron diversos lineamientos sobre cuestiones legislativas, como por ejemplo, el anteproyecto que luego de más de una década condujo a la sanción de la Ley 23.302 (Frites, 2011).

En 1973, por su parte, comienzan sus actividades las Federaciones Indígenas del Chaco y Tucumán (Lenton, 2010b: 91). Cabe aclarar que el período iniciado con la recuperación democrática en dicho año, se caracterizó por una encarnizada lucha política en el seno del peronismo gobernante, luego de 18 años de proscripción, lo cual dejó su impronta en el movimiento indígena nacional, el que no pudo evitar involucrarse en las disputas faccionales.

En 1974, a su vez, se convoca en Paraguay al Primer Parlamento Indoamericano del Cono Sur. Posteriormente, en 1975, se crea el Consejo Mundial de Pueblos Indios (CMPI) en Vancouver, Canadá y, en 1977, se realizan dos eventos importantes a nivel internacional. Por un lado, la II Declaración de Barbados, en la cual un grupo de dirigentes indígenas del continente describen y analizan las principales formas de dominación sufrida por los pueblos originarios, señalando principalmente a la política indigenista, el sistema educativo formal y los medios de comunicación. El otro acontecimiento fue la realización en Kiruna, Suecia, de la II Conferencia Mundial de Pueblos Indígenas.
En 1980, con la participación de dirigentes de Argentina, Bolivia, Brasil, Chile, Colombia, Ecuador, Paraguay, Perú, Surinam y Venezuela, se constituye el Consejo Indio de Sudamérica (CISA) en Ollantaytambo, Perú. En 1981 se realiza la III Conferencia Mundial de Pueblos Indígenas en Canberra, Australia. Para la misma época, surgen en Argentina, diversas organizaciones como la Asociación Indígena de la República Argentina (AIRA), el Centro Kolla (CENKO), diversas organizaciones representativas del pueblo mapuche en Norpatagonia y otras organizaciones en las diversas regiones del país.

Por otra parte, tanto durante la última dictadura cívico-militar (1976-1983), como a partir de la recuperación del régimen constitucional, la necesidad sentida, el reclamo fundamental de las distintas organizaciones, era obtener una legislación específica, la cual se logró en 1985 mediante la sanción de la Ley 23.302 de "Política Indígena y Apoyo a las Comunidades Aborígenes". Si bien en la actualidad dicho instrumento legal se encuentra desactualizado, resultó un hito en la histórica lucha de las organizaciones indígenas por su reconocimiento de derechos.

A dicha ley le siguieron las sanciones de las distintas legislaciones provinciales y el Congreso Indigenista Interamericano, realizado en San Martín de los Andes, provincia del Neuquén en 1988, donde se aprueba el Convenio 169 de la OIT, luego ratificado por Argentina en el año 2000 a través de la Ley 24.071, y en vigencia desde el 3 de julio del 2001.

Posteriormente, durante la década de los noventa, un número importante de organizaciones indígenas comenzaron a crear nuevos marcos organizativos y representativos alternativos a los existentes hasta entonces. 
Asimismo plantearon una agenda política diferente y confrontativa al modelo oficial vigente, buscando principalmente solucionar ciertos problemas estructurales como por ejemplo la cuestión territorial. Las distintas organizaciones indianistas de las provincias argentinas, en su gran mayoría, plantearon una política de duro enfrentamiento con los gobiernos provinciales y nacional, ante el embate de las políticas económicas neoliberales implementadas durante el decenio de gobierno del presidente Carlos S. Menem (1989-1999), que dejaron un saldo de debilitamiento del Estado, desempleo, corrupción, desindustrialización, concentración de la riqueza, degradación de las políticas sociales, con sus efectos principales: la desigualdad y exclusión social. Se manifestaron abiertamente en contra de la implementación de dicho modelo cuestionando también la política indígena oficial.

No obstante, algunos logros fueron obtenidos desde la acción oficial durante dicho período. Entre ellos se puede mencionar, hacia mediados de la década de los noventa, la puesta en marcha del Instituto Nacional de Asuntos Indígenas (INAI) ${ }^{4}$, que se encontraba pendiente desde su creación mediante ley nacional; y algunos proyectos provenientes de financiaciones externas que posibilitaron el fortalecimiento institucional, organizativo y la capacitación de dirigentes de algunas organizaciones.

Posteriormente, durante el año 1994, se produce la reforma de la Constitución Nacional, cuyo fin principal fue la concreción de la reelección presidencial, pero que posibilitó a su vez, la introducción de algunos instrumentos como el artículo $75^{\circ}$, inciso $17^{\circ}$, que constituyó un claro avance en el plano jurídico en cuanto a reconocimiento de derechos hacia los pueblos originarios ${ }^{5}$.
Dicho artículo establece que corresponde al Congreso:

"Reconocer la preexistencia étnica y cultural de los pueblos indígenas argentinos. Garantizar el respeto a su identidad y el derecho a una educación bilingüe e intercultural; reconocer la personería jurídica de sus comunidades, la posesión y propiedad comunitaria de las tierras que tradicionalmente ocupan; regular la entrega de otras aptas y suficientes para el desarrollo humano; ninguna de ellas será enajenable, trasmisible ni susceptible de gravámenes o embargo. Asegurar su participación en la gestión referida a sus recursos naturales y a los demás intereses que los afecten. Las provincias pueden ejercer concurrentemente estas atribuciones."

Asimismo, algunas provincias decidieron también modificar sus constituciones a los fines de reformular los artículos referidos a la población indígena. Jujuy (1986), Río Negro (1988) y Formosa (1991) lo efectuaron previamente a la reforma de la Constitución Nacional. En cambio Chaco (1994), Buenos Aires (1994), La Pampa (1994), Neuquén (1994 y 2006), Chubut (1994) y Salta (1998) lo hicieron con posterioridad a la misma.

Otro hecho importante en materia legislativa, fue la sanción en 2006 de la Ley 26.160, prorrogada en dos ocasiones (2009 y 2013), la cual declara la "Emergencia territorial en materia de posesión y propiedad de las tierras ocupadas por las distintas comunidades indígenas del país". Establece asimismo que no podrán efectuarse desalojos y encomienda al INAI, efectuar un relevamiento territorial (técnico, jurídico y catastral), en todas las provincias. Dicha ley constituyó parcialmente, un freno al avance especulativo de ciertas formas de "neolatifundismo" sobre los territorios indígenas, aunque los conflictos entre los gobiernos locales y ciertas organizaciones indígenas en algunas 
provincias (Neuquén y Formosa, por ejemplo), imposibilitaron su aplicación con total efectividad. En síntesis, podríamos caracterizar a la acción oficial en torno a la cuestión indígena llevada a cabo históricamente en la Argentina de la siguiente manera: a) desconocimiento generalizado a todo nivel de la cultura de los pueblos originarios. En caso de ser reconocidos, generalmente se lo hacía desde una visión empirista, preterista y estereotipada, basada en generalizaciones acríticas, positivistas y ahistóricas; b) inadecuación de las acciones llevadas a cabo, a las características específicas de las culturas indígenas (incluso en áreas tan sensibles como educación bilingüe e intercultural, territorialidad, salud y producción artesanal); c) falta de real participación protagónica de los destinatarios de las políticas diseñadas; d) carencia de objetivos generales comunes en todas las áreas; e) escasa coordinación entre sectores; f) ausencia de monitoreo y evaluaciones de las políticas y acciones ejecutadas; g) desconocimiento y falta de aplicación de instrumentos legales y disposiciones jurídicas del orden provincial, nacional e internacional referidos a la cuestión indígena; h) ausencia de políticas destinadas a la población indígena urbana.

\section{Consideraciones Finales}

A continuación detallamos algunas sugerencias que podrían tomarse en cuenta, como acciones concretas a desarrollar en un futuro inmediato, en términos de políticas estatales hacia los pueblos originarios.

1) Detectar y evitar las consecuencias/impactos y efectos de los distintos proyectos de infraestructura y grandes obras ${ }^{6}$ planificados en los territorios de las comunidades indígenas, acatando al respecto lo estipulado en el Convenio 169 de la OIT.
2) Evaluar el cumplimiento nacional y provincial de la legislación vigente, adecuando las normativas a los parámetros internacionales en materia de derechos de los Pueblos Indígenas y a la Constitución Nacional y promover la sanción de una Ley de Propiedad Comunitaria Indígena.

3) Revisar e incorporar en la administración de justicia, la relación entre el ordenamiento jurídico positivo y el derecho consuetudinario (no escrito). Lo cual implicaría la introducción de un pluralismo jurídico y la necesidad imperiosa de analizar las contradicciones del sistema legal vigente. Dicho pluralismo jurídico solo puede lograrse a través de un constitucionalismo transformador definido como: "Una constelación jurídica dominada por el cosmopolitismo tiende a favorecer la convivialidad. Solamente esta última respeta el principio de plurinacionalidad" (Santos, 2010:73).

4) Intensificar la aplicación de los derechos culturales de los pueblos originarios; tales como la educación bilingüe intercultural, los planes de estudio específicos, la participación de los miembros adultos de las comunidades en los procesos de enseñanza/aprendizaje, así como también la conservación, promoción, protección y el desarrollo de su patrimonio cultural tangible e intangible?

5) Fomentar y apoyar la recuperación de las memorias originarias, como mecanismo de construcción de conocimiento histórico "propio", que a la vez fortalezca los procesos de (re)construcción identitaria y de soberanía cognitiva.

6) Tomar en consideración a la población originaria urbana (que vive en pueblos y ciudades, en algunos casos superando el 90\%) (INDEC, 2006), a los fines de aplicar políticas específicas tal como menciona Frites, basándose en el Convenio 169 de la OIT; que: "(...) los Estados nacional y provinciales 
deben reconocer las organizaciones indígenas representativas de cada pueblo, en la medida en que en ellas se encuentren representadas las unidades sociopolíticas y económicas rurales o urbanas (...)" (Frites, 2011:106).

7) Tener en cuenta cuestiones cruciales de Derechos Humanos, como por ejemplo, los derechos económicos y sociales, con relación a la niñez indígena, en especial las niñas, en situaciones tales como migraciones, trata de mujeres, explotación del trabajo infantil. Los conflictos violentos y la violencia sexual hacia las mujeres son cada vez más manifiestos y con mayor impunidad, tal como diversas noticias en los medios de comunicación han transmitido recientemente . $^{8}$.

8) Facilitar la participación de los indígenas en los procesos de toma de decisiones, arreglos autonómicos, gobernanza y elaboración de políticas, con relación en particular al pleno ejercicio de los derechos civiles y políticos, en particular, ejerciendo la "Consulta previa, libre e informada". La vinculación del concepto de autonomía con los de pueblo originario y territorio, permite la construcción de distintas líneas y agendas políticas. La concepción de autonomía no se plantea como un simple reconocimiento de la diversidad cultural por parte del Estado, sino que a partir de la misma se exige que los pueblos originarios puedan lograr ejercer la autoridad y el control efectivo sobre su territorio. Dicho concepto suele ser caracterizado, más allá de los matices de las distintas organizaciones de cada grupo, como un espacio de la naturaleza que se encuentra bajo influencia cultural y el control político de un pueblo determinado. EI territorio es concebido además como un derecho natural, irrenunciable para la concepción filosófica y religiosa de los pueblos originarios.
Se trata, evidentemente, de conceptualizar una temática de gran complejidad, tanto en lo interpretativo como en cuanto a su aplicabilidad. En este sentido, la importancia del reclamo autonómico encuentra su justificación en el testimonio de Willemsen Díaz, quien afirma:

"Los pueblos indígenas tienen derecho a ejercer la autonomía y existen diversas formas de llevarlas a cabo. La autonomía dentro del Estado es una forma legítima y eficaz de dar vida a la igualdad de derechos humanos y libertades fundamentales.

(...) Elimina los temores secesionistas y no ataca ni afecta la integralidad territorial del Estado" (En Bengoa, 2007: 282-283).

Por otra parte, no se debe incurrir en el error de conceptualizar a las entidades autónomas como homogéneas e igualitarias per se, dado que no pueden soslayarse las diversas y complejas situaciones de desigualdad y heterogeneidades internas existentes y, que plantean además, una compleja dialéctica entre los intereses generales y particulares.

9) Atacar las distintas formas antiguas y modernas de discriminación y racismo hacia los pueblos originarios, por lo cual se hace necesario tener en cuenta entre otras, las recomendaciones emanadas de la Declaración y del Programa de Acción de la Conferencia Mundial contra el Racismo, la Discriminación Racial, la Xenofobia y las Formas Conexas de Intolerancia.

En síntesis, los pueblos originarios de Argentina sufrieron una serie de transformaciones durante la segunda mitad del siglo XX y la primera década del presente, las cuales pueden encuadrarse de acuerdo con Ribeiro (1971) y, Bartolomé \& Barabas (1996), bajo el concepto de "proceso de transfiguración étnica" o, el "revival de lo étnico 
(Vázquez, 2000:41) y que constituyen actualmente, el anclaje desde el cual plantean sus reivindicaciones como pueblos ${ }^{10}$. Asimismo, dichas transformaciones adoptan una serie de indagaciones en el pasado histórico y mitológico, con el fin de articular una estructura político/organizativa basada en la identidad étnica que posibilite el alcance de una soberanía cognitiva. De este modo, la etnicidad reaparece o (re)emerge de un modo más activo y poderoso que en otros contextos históricos y de una manera claramente articulada, como respuesta ante nuevas situaciones, manteniendo y reforzando los "límites" cuando estos se encuentran bajo la presión de compulsiones asimilacionistas. Se trata de un momento político desarrollado durante lo que Bengoa denomina como "posindigenismo" (Bengoa, 2007), cuando los movimientos indígenas comienzan a desarrollar "estrategias de poder" (García Linera, 2007), a través del surgimiento y fortalecimiento de movimientos etnopolíticos, superando situaciones de cooptación estatal y con agendas políticas que dejan atrás los meros reclamos "asistencialistas" y las actitudes "defensivas".

En esta etapa es el propio Estado, en sus diversas versiones, el que comienza a ser cuestionado e interpelado desde dichos movimientos. Aquí nos encontramos con discursos políticos que basan su accionar en describir el modo en que los pueblos originarios sufrieron el accionar del Estado en sus distintas manifestaciones históricas (colonial, liberal, populista, desarrollista, autoritario, de mercado). Por otra parte, cabe agregar que en la actualidad las organizaciones indígenas en el marco de este proceso, relacionado con los conflictos que mantienen con el Estado en sus distintos niveles, como así también frente a diversos factores de poder que responden a intereses variados, expresan alternativas y estrategias de lucha de gran utilidad en ciertas coyunturas, no obstante el hecho de producirse en el marco de un sistema interétnico cuyas características fundamentales están constituidas por relaciones de dominación/subordinación generadoras de discriminación y desigualdad social.

De esta manera, las estructuras organizativas (re)creadas durante las últimas décadas poseen diversos grados de representatividad, contando con distintos niveles de sustentación respecto a sus bases sociales y comunitarias. En las distintas provincias, los partidos políticos gobernantes impulsan sus agendas hacia las comunidades y organizaciones, mientras que éstas intentan hacer lo propio en un proceso no exento de tensiones y contradicciones, que oscilan entre el enfrentamiento abierto y la cooptación bajo la forma de etnoclientelismo político.

En algunas provincias (v.g. Salta, Formosa y Neuquén); el enfrentamiento entre algunas organizaciones y los gobiernos provinciales ha conducido a formas de violencia y de represión de las protestas con marcada virulencia (asesinatos impunes, judicialización de los reclamos, procesamiento de dirigentes, manipulación del miedo, desalojos compulsivos y usurpación de territorios). Todo ello en un marco de manipulaciones informativas cuya base argumental en algunos casos suelen ser diversas formas de racismo y etnofobia como expresiones de intolerancia y discriminación.

Finalmente, resulta imprescindible aclarar que entre las variadas organizaciones etnopolíticas que actúan en las distintas regiones del país, no existen formas de expresión política homogéneas, continuas y estables. Asimismo, la movilización étnica, en su intensa dinámica, adopta modalidades 
diversas, tanto en la expresión del discurso como así también en el diseño de agendas y en las prácticas políticas concretas, quedando sujetas a las constantes contradicciones, transformaciones y vaivenes que las articulaciones políticas provocan en los diversos niveles.

\section{Notas}

${ }^{1}$ Según Bachelard, “(...) la pasión por la interioridad constituía una de las formas privilegiadas por las cuales las fantasías (elaboradas sobre la base del sentido común) penetraban en el discurso científico, obstaculizando su racionalidad" (Bachelard, 1970).

${ }^{2}$ La crítica a la antropología se centraba en que: "Desde su origen la Antropología ha sido instrumento de la dominación colonial, ha racionalizado y justificado en términos académicos, abiertos o subrepticiamente, la situación de dominación de unos pueblos sobre otros y ha aportado conocimientos y técnicas de acción que sirven para mantener, reforzar o disfrazar la relación colonial. América Latina no ha sido excepción y con frecuencia creciente programas nefastos de acción sobre los grupos indígenas y estereotipos y distorsiones que deforman y encubren la verdadera situación del indio pretenden tener su fundamento científico en los resultados del trabajo antropológico" (Documentos de la Primera Declaración de Barbados: "Por la liberación del Indígena", Bridgetown, 30 de enero de 1971:4).

${ }^{3}$ Se trató de la participación de un grupo de antropólogos de distintos países (Miguel A. Bartolomé, Nelly Arvelo Jiménez, Guillermo Bonfil Batalla, Esteban E. Mosonyi, Víctor D. Bonilla, Darcy Ribeiro, Gonzalo Castillo Cárdenas, Pedro Agostinho da Silva, Miguel Chase-Sardi, Scott S. Robinson, Silvio Coelho dos Santos, Stefano Várese, Carlos Moreira Neto y Georg Grünberg), en el Simposio sobre la fricción interétnica en América del Sur, auspiciado por el Programa de Lucha con el Racismo del Consejo Mundial de Iglesias, llevado a cabo en Bridgetown, Barbados entre los días 25 y 30 de enero de 1971.

${ }^{4}$ El sector del Estado vinculado con la política indígena a nivel nacional estuvo instalado en diversos organismos de acuerdo con las diferentes coyunturas políticas ocurridas en la historia contemporánea del país. Durante las últimas décadas del siglo XIX (aproximadamente 30 años), formó parte del Ministerio de Guerra. A partir de 1912 pasó al Ministerio del Interior donde se mantuvo durante otras tres décadas. En 1943, es incorporado a la Secretaría de Trabajo y Previsión, ocupada en ese entonces por el coronel Juan D. Perón, como paso previo a su ascenso a la Presidencia de la Nación mediante elecciones en 1946. En 1949, durante el primer gobierno peronista, la temática indígena fue delegada a la Dirección Nacional de Migraciones del Ministerio de Relaciones Exteriores, durante aproximadamente seis años, hasta que a partir del golpe militar de 1955 retorna al Ministerio del Interior. Durante el gobierno desarrollista de Arturo Frondizi, en 1958, el área se incorpora al Ministerio de Trabajo y Seguridad Social. En 1967, luego del golpe militar del general Juan C. Onganía, se desplaza al Ministerio de Bienestar Social, en la Secretaría de Asistencia y Promoción de la Comunidad. Finalmente en 1992, durante el primer gobierno de Carlos $\mathrm{S}$. Menem, se pone en marcha el Instituto Nacional de Asuntos Indígenas (INAI), creado mediante la Ley 23.302 de 1985, formando parte de la Secretaría de Desarrollo Social, hoy convertida en Ministerio, en donde continúa.

${ }^{5}$ La anterior Constitución Nacional de 1853, contenía elementos discriminatorios como el establecido en el art. $67^{\circ}$, inciso $15^{\circ}$; referido a las atribuciones del Congreso de la Nación, el cual indicaba: "Proveer a la seguridad de las fronteras, conservar el trato pacífico con los indios y promover la conversión de ellos al catolicismo". La reforma de 1994 eliminó dicho artículo reemplazándolo por el art. $75^{\circ}$ inc. $17^{\circ}$.

${ }^{6}$ La explotación de gas y petróleo, es una de las formas de extractivismo que mayor impacto socioambiental ha provocado en comunidades mapuches de la provincia del Neuquén en la Patagonia Norte. Un total de 18 comunidades, sufren este tipo de impactos. Las empresas Pluspetrol-Enarsa mediante una concesión realizada en 2007 en las zonas de Zapala y Laguna Blanca en el centro de la provincia, afectan a 12 comunidades mapuches. Repsol por su parte, produjo uno de los más graves estragos ambientales en el rico yacimiento de Loma de la Lata, 
en donde fueron afectadas las agrupaciones Painemil y Kaxipayiñ. Las restantes empresas responsables de afectar el territorio mapuche han sido Apache, Total, Chevron, Fox Petrol y Piedra del Águila. Otro hecho que despierta mucha preocupación en estas comunidades del área de Loma de La Lata es el reciente inicio de la explotación de hidrocarburos no convencionales (shale oil y shale gas) (Radovich, 2013). Las grandes represas hidroeléctricas, la explotación minera, el turismo y la expansión de la frontera agrícola mediante la ampliación de la superficie sembrada con soja, constituyen las amenazas territoriales más importantes hacia la territorialidad indígena.

${ }^{7}$ En el plano educativo, los porcentajes más elevados de jóvenes con la escuela primaria incompleta lo poseen los pueblos mbyá-guaraní $(54,1 \%)$; wichí $(52,4 \%)$ y Qom (50,4\%), de acuerdo con un estudio efectuado por UNICEF, Centro de Estudios de Población y la Asociación de Juventudes Indígenas (Página 12, 29/04/2011:21).

${ }^{8}$ En la localidad de Las Lomitas, provincia de Formosa durante el año 2013 un juez dejó en libertad a un violador de 29 años quien habría abusado de una niña aborigen de 12 años, bajo el argumento que "(...) el hombre hizo lo que hizo porque la niña lo habría provocado (...) otros caso similares, perpetrados por el hijo de un policía contra otra niña (aborigen) de igual edad, en Pozo del Tigre, y por un gendarme contra una adolescente (aborigen) de 16. El juez los liberó a ambos" (Cecchini, 2013:10)".

${ }^{9}$ En 2012 y 2013, durante la propuesta de reforma del Código Civil y Comercial de la Nación, se plantearon una serie de dudas respecto a los componentes relacionados con los pueblos originarios, en particular lo atinente al derecho a la posesión y propiedad comunitaria de las tierras y la participación en la gestión de los recursos naturales, dado que el nuevo Código solo consideraría a aquellas comunidades con personería jurídica reconocida. Otra objeción a la propuesta de reforma es la que considera a las comunidades indígenas personas jurídicas de derecho privado en lugar de personas de derecho público, dado que ello implicaría desconocer lo establecido en la Constitución Nacional, la cual reconoce a las comunidades como preexistentes al Estado Nacional (Facultad de Filosofía y Letras-UBA, 2012).
${ }_{10}$ Un ejemplo de ello, lo constituyen el número de comunidades indígenas reconocidas por el Estado nacional a través del INAI. En el año 2009 estaban registradas 1.106 comunidades, mientras que en 2012 dicho número había aumentado a 1.333, con un crecimiento del 20,5\% (INAI, RENACI-Registro nacional de comunidades indígenas).

\section{Referencias bibliográficas}

Bachelard, G. (1970). L'idealisme discursif. Études. Paris: Vrin.

Balazote, A. \& Radovich J. (1999). "Present situation of Indigenous Peoples in Argentina". En IMO Bulletin, Cultur Link, Network of Networks for Research and Cooperation in Cultural Development, № 28, Vol. 10: 157-163, Institut za Medunarodne Osobne (IMO). Zagreb, Croacia, August.

Bartolomé, M. \& Robinson, S. (1984). "Indigenismo, dialéctica y conciencia étnica". En C. Junquiera et.al. Los indios y la antropología en América Latina. Buenos Aires: Búsqueda.

Bartolomé, M. \& Barabas, A. (1996). La pluralidad en peligro. México: INI.

Bengoa, J. (2007). La emergencia indígena en América Latina. Santiago: Fondo de Cultura Económica.

Briones C. \& Carrasco, M. (2000). "(Neo) indigenismo estatal y producciones indígenas en Argentina (19851999)". XII Reunião da Associação Brasileira de Antropología.

Cecchini, D. (2013). "Cadáver nos van a sacar de acá". La comunidad de Campo del 20, cerca de Las Lomitas, resiste pacíficamente al desalojo de sus tierras ancestrales. Miradas al Sur, 10 de junio.

Facultad de Filosofía y Letras-UBA (2012). Declaración del Consejo Directivo (CD) ante el proyecto de reforma, actualización y unificación de los Códigos Civil y Comercial de la Nación. 23 de octubre.

Frites, E. (2001). El derecho de los pueblos indígenas. Buenos Aires: PNUD-Rosa Guarú-INADI.

García Linera, A. (2007). "El desencuentro de dos razones revolucionarias: indianismo y marxismo". Cuadernos del Pensamiento Crítico Latinoamericano, № 3, diciembre, CLACSO. 
(2008). La potencia plebeya. Acción colectiva e identidades indígenas, obreras y populares en Bolivia. Buenos Aires: CLACSO/Prometeo.

Gorosito Kramer, A. (1992). Identidad étnica y manipulación. En C. Hidalgo \& L. Tamagno (Comps) Etnicidad e Identidad, pp.143-153. Buenos Aires: CEAL. Hidalgo, C. \& Tamagno, L. (1992). Etnicidad e Identidad. Buenos Aires: CEAL.

INDEC. 2006. Encuesta Permanente de Pueblos Indígenas (ECPI). Versión abreviada. Estudios 46; Buenos Aires: INDEC.

Kropff, L. (2005). "Activismo mapuche en Argentina: trayectoria histórica y nuevas propuestas". En Pueblos Indígenas, Estado y Democracia, P. Dávalos (Comp), Buenos Aires, Grupos de Trabajo, CLACSO, pp. 103-132. Lenton, D. (2010a). "Política indigenista argentina: una construcción inconclusa". Anuario Antropológico; Brasilia, Año 2010, vol. 2009, pp. 57-98.

(2010b). "Políticas del estado indigenista y políticas de representación indígena: propuestas de análisis en torno al caso neuquino en tiempos del desarrollismo". Sociedades de Paisajes Áridos y Semiáridos. Año II, Vol. II; junio: 85-108. Universidad Nacional de Río Cuarto.

Páez, J. (1970). La Conquista del Desierto. Buenos Aires: CEAL.

Rabey, M. \& Blaser, M. (1994). "Contextos de conversación, los líderes étnicos y sus interlocutores". En Karasik, G. (comp.) Cultura e identidad en el Noroeste argentino. Buenos Aires: CEAL, pp.146-168

Radovich, J. \& Balazote, A. (comps.) (1992). La problemática indígena. Estudios antropológicos sobre pueblos indígenas de la Argentina. Buenos Aires: CEAL. (1999a)."La resistencia indígena en América.

Las nuevas organizaciones". En: Eco, Año 7, № 15, Mayo-julio de. Buenos Aires.

(1999b). "Estudios antropológicos sobre la cuestión indígena en la Argentina”. La Plata: Ed. Minerva. (1999c) "La resistencia étnica de los pueblos indígenas de Argentina". El Faro de Latinoamérica; №3, Buenos Aires.

Radovich, J. (1992) "Política Indígena y Movimientos Étnicos: el caso Mapuche". Cuadernos de Antropología, №4: 47-65. Universidad Nacional de Luján (UNLu). (1999a) "Del paternalismo a la autogestión.

Transformaciones en la política indígena en la Argentina". En Radovich, J. \& Balazote, A. (Comps.). Estudios antropológicos sobre la cuestión indígena en la Argentina. La Plata: Minerva.

(1999b). "Etnicidad y fronteras ante la globalización: las organizaciones mapuches en la Argentina". En J.J. Pujadas Muñoz et. al. (Coords.) Globalización, Fronteras Culturales y Políticas y Ciudadanía: 157169. FAAEE, Santiago de Compostela. (2007). "Multiculturalidad en la Argentina: legislación, minorías y discriminación en las políticas oficiales". En Interculturalidad en los procesos de la formación identitaria de América Latina: Percepciones e interpretaciones (Slobodan S. Pajovic; Coord.). Belgrado: CEISAL y Universidad Megatrend, pp.117-131. (2011). "Los pueblos originarios de la Argentina. Situación actual”. En M. Bovisio \& Radovich, J. Arte Indígena en tiempos del Bicentenario. Buenos Aires: Secretaría de Cultura de la Nación. (2013). "Los mapuches y el Estado neuquino: algunas características de la política indígena". RUNA. Archivos para las Ciencias del Hombre. Vol. 34, № 1. ICA-FFyL-UBA. E/P.

Reynoso, C. (1988) Antropología y Derechos Humanos. Primer Certamen Literario 1984: "Derechos Humanos". Asamblea Permanente por los Derechos Humanos. EUDEBA. Buenos Aires.

Ribeiro, D. (1971). Fronteras indígenas de la civilización. México: Siglo XXI.

Santos, B. (2010). Refundación del Estado en América Latina. Perspectivas desde una espistemología del Sur. Buenos Aires: Antropofagia.

Serbin, A. (1981). "Las organizaciones indígenas en la Argentina”. América Indígena, XLI (3): 407-433.

Slavsky, L. (1987). "Indigenismo, etnodesarrollo y autonomía". Revista de Antropología, Año 2, № 2, pp.19-26, Abril, Buenos Aires.

Tamagno, L. (2009). Pueblos Indígenas. Interculturalidad, colonialidad, política. Buenos Aires: Ed. Biblos.

Trinchero, H. \& Leguizamón, J. M. (1995). "Fronteras de la Modernización. Reproducción del capital y de la fuerza de trabajo en el umbral al Chaco argentino". En H. Trinchero (ed.) 
Producción Doméstica y Capital. Estudios desde la Antropología Económica. Buenos Aires: Biblos.

Tamagno, L. (2009). Pueblos Indígenas. Interculturalidad, colonialidad, política. Buenos Aires: Ed. Biblos.

Trinchero, H. \& Leguizamón, J. M. (1995). “Fronteras de la Modernización. Reproducción del capital y de la fuerza de trabajo en el umbral al Chaco argentino". En H. Trinchero (ed.) Producción Doméstica y Capital. Estudios desde la Antropología Económica. Buenos Aires: Biblos.

Tur, C. (1972). Colonias y colonizadores. Buenos Aires: CEAL.

Valverde, S. (2003). "Etnicidad y lucha política: Las organizaciones indígenas de Río Negro". I Jornadas de Jóvenes Investigadores en Antropología Social (Buenos Aires: Sección de Antropología Social, FFyL, UBA), publicación en CD.

Viñas, \& Gastiazoro, E. (1968). Economía y dependencia (1900-1968). Buenos Aires: Carlos Pérez. 